\title{
Designing a Knowledge Network Model of Research Institute of Petroleum Industry
}

\author{
Gholamhosseinzadeh, $\mathrm{Z}^{1} \quad$ Riahinia, $\mathrm{N}^{2 *}$ \\ 1.P.h.D Library and information sciences, Kharazmi University and Knowledge manager in Research Institute of \\ Petroleum Industry (RIPI), Tehran, Iran \\ 2.Full professor, Library and Information Science department, kharazmi university, Tehran, Iran
}

\begin{abstract}
Objective: The present study aims to design a research network model of Research Institute of Petroleum Industry.

Method: This study is applied in terms of the target type, and based on approach, is a hybrid research method. In this research, a semi-structured interview was used to collect the required data on the modeling of the model, and a questionnaire was used to collect quantitative data. In the qualitative method, semi-structured interviews have administrated to 9 managers and experts of the Research Institute of Petroleum Industry who selected through purposeful sampling. Thematic analysis method was used for analysis the interviews and explanation of related dimensions and components. Then, 226 key projects managers were asked to answer a number of specific questions to collect quantitative data.

Findings: According to the data analysis, 9 dimensions of the knowledge network (the strategic dimension, structure, background, environmental factors, and knowledge sharing culture, the content of knowledge network, infrastructure, motivation, and mission) identified. The variance of exploratory factor analysis of $75 \%$ showed that 9 factors of knowledge network constitute the Petroleum Industry Research Institute. Based on the identification of the dimensions of the knowledge network, its initial model depicted. The results of confirmatory factor analysis also indicated that each of the nine dimensions of the knowledge network has a very favorable overall yield of between 0.77 and 0.61 , and the model has fit.

Conclusion: The results of this study showed that the multidimensional nature of the knowledge network of the Research Institute of Petroleum Industry has linked to the mental models of the interviewees and in joint action, has led to the successful knowledge management at the research institute. The results of the research for the Research Institute of Petroleum Industry provide the opportunity for the managers of the organization to prevent the damage caused by the failure of the plans by the adoption of solutions for the creation or reform of the infrastructure due to the weakness of each of the factors.
\end{abstract}

Keywords: Knowledge, Knowledge Network, Research Institute of Petroleum Industry

DOI: $10.7176 / \mathrm{IKM} / 9-2-02$

\section{Introduction}

The third millennium is the knowledge-based era. In this era, knowledge is the most crucial asset of organizations and countries (Monavvarian and Asgari, 2009). In the current unstable situation, Nonaka believes that the only reliable source for gaining sustainable competitive advantage is knowledge. Knowledge management is one of the topics that are of great importance today in organizations. One of the main efforts of knowledge management is the dissemination of knowledge and its application in practice for the survival of the organization and the creation of competitive advantage in the field of organizational competition. Sharing knowledge has been raised as one of the main concerns of managers and organization leaders and the primary goal for investment (Hassanzadeh, 2008). Researchers today find that the mere existence of knowledge workers does not lead to a competitive advantage in the product, but also a behavioral knowledge sharing between them that brings competitive advantage to the organization. For this reason, exchange and knowledge sharing are recognized as one of the most important processes of knowledge management (Beig et al., 2011).

Okunoye (2003) believes that without a deep understanding of knowledge sharing, knowledge management is in vain. Because even if other components of knowledge management completed, if the sharing and development of knowledge in the organization are not carried out, the other stages are also sterile, so the knowledge provided remains with only a few people and will not develop. Consequently, the co-creation and creation of new knowledge that occurs during the sharing of knowledge and organizational learning do not take place, and this knowledge is eliminated from time to time and is unusable. If the valuable knowledge of the organization loss, it will probably go to destruction. On the other hand, this researcher introduces knowledge networks as a key factor in understanding the process of sharing and knowledge flow, and believes that knowledge sharing and the knowledge network are inextricably interconnected, and there is a positive relationship between these two, which will result in the development of better and more successful adaptation to the changing environment (quoted in Sheng et al., 2013).

There have been official networks of artists, merchants, and craftsmen from the past. Therefore, it argued 
that the existence of knowledge networks has a long history. Today, these networks considered as one of the knowledge management empowers in organizations that encourage exchanges of views and experiences among individuals. So, understanding the value of these networks in the organization can play a crucial role in the success of effective applying of knowledge. Awareness of the performance of knowledge networks is precisely the key to the survival of the individual in the organization (Johnson, 2009).

Seufert (2006) argues that knowledge networks are networks in which knowledge and experience flow around a range of issues, especially key issues. In the meantime, new knowledge is created, procedures are improved, and vital issues are addressed or focused on a particular policy or debate. Such a network can be formed in different ways; it can be an informal network in which exchanges of highly diverse contributors or relatively organized and has fixed members, as well as continuous exchanges and high coordination. Therefore, the focus of the knowledge network is not limited to the explicit knowledge of the organization for the full realization of the use of organizational knowledge in order to create value. Focusing on tactic knowledge which is institutionalized in the member's mind is considered (Seufert et al., 2006).

Although organizations perceive the importance of the knowledge network, they still have difficulty building it. Also, despite numerous studies in the field of networking, research and work on knowledge networks in developing countries, especially Iran, has been more focused on scientific networks, and less has been the focus of knowledge networking. One of the reasons for this is the lack of funding for these networks, the lack of interest in sharing knowledge and discourse among managers and staff, the existence of formal structures and the lack of participation culture among employees

The Research Institute of the Petroleum Industry, as the research center in the field of oil, gas, and petrochemicals in Iran, localizes a major part of the needs of the country's oil industry. According to research institute positions in oil and gas industry, the presence of experts in different areas is one of the most important challenges that managers of the research institute are currently dealing with. Lack of proper knowledge communication and knowledge sharing among research institutes and departments, Development of knowledge (implicit and explicit) with regard to carrying out various projects in different fields of the Research Institute of Petroleum Industry and the need to create a suitable platform for the acquisition and transfer of these knowledge, Not using all the abilities of researchers and outsourcing many tasks and projects outside the Research Institute, Definition of Proposals and Repetitive tasks at the Research Institute of Petroleum Industry (Kamali Tabrizi, 2011).

One of the reasons for these problems is that even when people know what they are looking for, they do not know where to look for it. The number of questions of "Does anyone know?" could be a sign for the Research Institute of Oil Industry, which means that people in this research institute are unaware of where required knowledge is. In this regard, the need to establish a network of knowledge of the research institute of oil industry officially with the goals of facilitating access to scientific and specialized resources; the achievements and results of researchers; sharing and creating knowledge; identifying and accessing managers and professionals; and interacting with them in a completely free and competitive, is evident.

Therefore, Considering the importance of knowledge network for research centers (research institutes) the researcher in this research seeks to answer two questions: 1. what are the components of the knowledge network in the Research Institutes in particular the Research Institute of Oil Industry? 2. What is the conceptual framework (model) for the knowledge network in the Research Institute? 3. Is the conceptual framework (model) valid?

\section{Literature Review}

The investigations carried out by the researcher showed that so far, no research has been done to provide a suitable model of knowledge network so far for research centers such as the Research Institute of Petroleum Industry. Therefore, in the present research, an attempt is made to reduce the hierarchical relationship and to provide the appropriate conditions for more collaboration among staff, and the appropriate model for creating a knowledge network at the Research Institute. Therefore, this study seeks to answer the main question, which model can be introduced for the knowledge network in the research institution.

Reviewing the background of the study in the field of knowledge networks indicates that the Most studies conducted in this field in recent years, which have been considered by domestic and foreign researchers, are in continuation as a part of a number of important researches in the area of the knowledge network.

Seufert et al. (2006) in their research entitled "Creating Knowledge Networks" they have focused on the fact that organizations are increasingly moving from a well-structured and manageable system to a complex system with ambiguous boundaries. Such organizations are neither fully independent of one another, nor are they entirely dependent on each other. These organizations have not lost their legal identity, accordingly, retain their culture and management structure, and pursue their own strategies. On the other hand, they reduce their autonomy and act jointly in decision-making processes. The organizational structure is interconnected and brings together some of the activities or operations, and leaves the organization's culture open to external influences. 
The researchers believe that a network vision for future knowledge management is needed. Thus, they presented an integrated view of the knowledge network in their research work, and developed a framework. The components of the framework provided by these researchers include facilitating circumstances, internal structure and cultural dimensions, knowledge work processes, and knowledge architecture. From their point of view, the trend toward networked organizations is not limited to just a few industries and companies and can involve all organizations.

Dantas (2006) in his research "Developing Knowledge Networks in Innovative Systems" the case study of Brazil's Petrobras Corporation addresses the overlooked questions about developing knowledge-based networks of knowledge, prior to the learning and innovation systems in the industrialized economies. Their focus is on the oil industry, where knowledge networks of large oil companies and technology users play a vital role in innovation systems. The network studied by these researchers is the Petrobras Knowledge Network or the Brazilian Oil Company. In their research, they have investigated the relationship between company capabilities and the characteristics of knowledge networks. In other words, Map absorption capacities in the use of existing networks and the ways in which the network can be used to strengthen these capabilities were studied. In their study, they also investigated the evolution of the interoperability of company capabilities and company-centric networks over the past 30 years and the late 1960s to the early 21 st Century. In this research, there is a cohesive, non-repetitive, and self-enhancing relationship between capabilities and networks. The results of this study revealed that the capabilities and knowledge networks of an organization change over time and done in a nonrepetitive, self-enhancing, and aggregate process. The point in this research is how the capabilities of the organization and the result of changes in these capabilities have created knowledge networks. One of the main points of this research is to identify the importance of organizational capabilities as a factor in creating knowledge networks focused on Petroleum companies. The framework presented in this study is suitable for analyzing the evolution of network shapes that exist in industrialized countries such as Iran.

Whitall (2007) in the research entitled "Network Analysis of the Common Government System" sought to answer the question of how network characteristics affect network performance. The findings of this study indicate that networking is actually a response to increasing demand for participation. The results of the research indicate that there is a direct relation between the network characteristics and its performance.

Johnson (2009), in his research entitled " Knowledge Networks Management " discusses topics such as knowledge and its types, network analysis, the role of actors in the network, the design of knowledge networks, the technologies needed to create knowledge networks, spatial distribution of knowledge, decision making in the network, the role of man in the network, creativity and innovation, and management of knowledge networks. In the design section of the Knowledge Network, the researcher has expressed his knowledge of the network's design based on the organization's formal structure and own ascending, descending, and horizontal communications design.

Tang (2010), in his master's thesis entitled "The Role of Knowledge Networks in Knowledge Transfer Process" aims to study the role of networks in the process of knowledge transfer by using various theories as the basis of work and to link research backgrounds with experimental data has stated. The method is a qualitative research in which secondary data such as company information from the website and annual report is collected. Interviews were also held with the directors of two international companies, industrial networks HMS AB and Sinowayt? Joint Stock Company. Interviewees are workers who have been involved in communication with foreigners. Findings of the research indicate that all major networks, including national networks, etc. are critical factors in the process of knowledge transfer. National Domestic Network acts as "counseling" and provides guidance for learning. The national host network acts as an input tool and helps companies to enter the foreign and unknown markets through difficult linguistic and cultural barriers. Sub-networks act as an "increasing knowledge". They act together in transferring knowledge between host countries to strengthen the whole process. in conclusion, it has outlined its conceptual model for transferring knowledge between the internal, local and sub-networks.

Pugh and Prusak (2013), The Researchers in their Study Seek to Better Understand the Factors through which Network Leaders can Derive results and products from the knowledge network. In this study, researchers have detailed the goals of establishing "Knowledge Networks in ConocoPhillips and the Women World Bank. They continue to provide a framework in which to effectively manage the knowledge network. Finally we can conclude that, in order to realize the knowledge network, three aspects and seven components have been introduced. Due to these aspects, the knowledge network can be created more efficiently. This model is beneficial for Profitable and Unprofitable organizations in all aspects in order to learn more quickly and contribute to the people.

Du Preez (2016) in his research entitled "A Comparative Study on the Official Design of the Life Cycle of Integrated Knowledge Network in Support of Innovation" addressed the role of networks in supporting innovation. He states that the use of knowledge networks is effective in empowering groups to progress while using collective experience and applying competitive knowledge. The researcher also points out that collective 
experiences can only be used if they are structured in such a way that this knowledge is available to other members of the team. He also studied the concepts of integrated knowledge networks and how successful this type of network has been in terms of improving the process of creating knowledge. In his study, he proposed a method for integrating the knowledge network. Has introduced the following requirements: Knowledge network goals: Why is there a knowledge network? Functional requirements of the knowledge network: What are the functions of the knowledge network to carry out and meet the intended purpose? Methodology Requirements of Knowledge Network: What is the methodology used to design, create, deploy, refine and phase out the knowledge network? (Control and measurement of objectives) In this research, the integrated knowledge network structure based on four phases of design, implementation, operation and refinement and withdrawal is presented. In the study, the researcher introduced his proposed framework, which consists of 14 aspects, and six examples of the centers that underlie this framework have also been introduced in this study. In conclusion, the factors of success and barriers to the formation of knowledge networks are mentioned.

Researches carried out inside the country (Iran) show that since 2009 the severe research network has been conducted in the area of knowledge network, which itself indicates that the subject of the knowledge network is a new field that has been considered by researchers inside the country in recent years. Some of these studies are mentioned below.

Asgari et al. (2014), in their research entitled "The Role of Knowledge Management Infrastructure in the Implementation of the Organization Knowledge Network," investigated the knowledge management infrastructure in the implementation of the Knowledge Network. The purpose of this research was to investigate the role of knowledge management infrastructure in implementing the knowledge network of Islamic Azad University Ghaemshahr Branch in terms of faculty members of the university. Using the krejcie and Morgan tables, 169 people were selected as the statistical sample of 587 people. The research method is survey study and its data were collected by using a questionnaire. The final coefficient was obtained by using Cronbach's alpha of 0.8. According to the analysis, the level of familiarity of university faculty members with the concept of knowledge management and knowledge network was reported at a low level. Moreover, among the factors under investigation, four factors of organizational culture, organizational structure, processes and financial resources were in an inappropriate situation and the two factors of human resources and technology infrastructure were in a proper position.

Karimi et al. (2014) in his research entitled "Investigating Mechanisms of Knowledge Sharing Networks from the Corporate Governance System" point out to the knowledge sharing as the main challenges in the knowledge management cycle. The purpose of the researchers is to investigate the mechanism of the impact of the knowledge transfer process on knowledge networks, inspired by modern theories of knowledge transfer and sharing, social networks, and corporate governance system. In this study, researchers have offered strategies that can influence knowledge sharing in networks. Examples include fame, norms, ethical behaviors, contracts, and trust. Finally, the researcher presented the conceptual model of the research. In the presented model, the key to the relationship between knowledge networks and the corporate governance system is issues related to knowledge overflow and prison imprisonment. The impact aspects of the knowledge transfer from the viewpoint of these researchers include: 1. Reputation mechanisms 2. Coalitions 3. Norms 4. Common ethical behaviors 5. Role 6. Concentration 7. Trust.

Davari (2015), has introduced his master's thesis entitled "The Study of Factors Influencing the Implementation of the Common Knowledge Network between Collaborative Organizations (Case Study of the Petrochemical Industry)", which is one of the main pillars of knowledge management, and also knowledge sharing at the internal levels of the organization, as well as with other Organizations, especially collaborating organizations, and the establishment of a coherent network of inter-organizational knowledge. This study aimed to identify and explain the factors affecting the joint implementation of knowledge network among cooperative organizations and the study of the relationship between effective factors and the achievements of the network implementation in the petrochemical industry. The research method is survey study and its data were collected by using a questionnaire. Based on the results of this study, five factors associated with knowledge holders, knowledge receptors, interagency collaboration framework, the nature and content of knowledge, and hardware and software infrastructure have been introduced as factors in creating an interorganizational collaborative knowledge network. The results of Pearson correlation test showed that there is a significant positive correlation between effective factors and achievements of joint knowledge network implementation among co-organized organizations.

Haghbin and et al. (2015), in his research entitled "Identifying the Key Indicators of the Establishment of Knowledge Networks in Tehran University of Science and Technology Parks" identified the key indicators of knowledge networking based on network mapping, and the determination of the intensity of the impact and the effectiveness of indicators with Dematel technique. In this research, also considering the performance of Tehran Science and Technology Park, some strategies have been introduced to improve knowledge management processes. Finally, the model of knowledge network development for knowledge-based companies is presented 
in four dimensions of culture, technology, processes of knowledge and human resources.

By studying the internal and external backgrounds and the models presented by several scholars, the researcher has identified the following gaps:

1- In the model presented by Dantas (2006), which is based on the Petrobras network, factors such as organizational factors, technology, organizational regulations, management procedures and company capabilities are mentioned as factors affecting the knowledge network. Unfortunately, in this model, the most important aspect of human factors is not mentioned. Also it is the conceptual model not applicable.

2- In the framework provided by Tang (2010), only the internal, local and sub-networks are mentioned without mentioning factors affecting the network.

3- In the framework provided by Seufert et al. (2006), one can see the facilitator of internal structure, cultural aspects, work processes and knowledge architecture as components of the model. But in this model, there are no environmental, social and political factors that can be considered as external facilitators.

4- The framework provided by Du Preez (2016) focuses more on the deployment of the knowledge network, and only part of it is in the design of the knowledge network. This framework is presented for the integrated networks of inter-organizational knowledge.

5- The aspects provided by Pugh, K. and Prusak (2013) for the knowledge network consist of three strategic, tactical and design, and seven components (having purpose, role of skill, inclusion, participation, operational model, infrastructure, and facilitating social standards). Researchers have not referred to a specific framework in this study. Also, the content of knowledge and the role of network members and environmental influential factors are not mentioned.

6- In the model presented by Davari (2015), only the sharing of inter-organizational knowledge and the factors affecting this subscription has been noted.

7- The model presented by Haghbin et al. (2015) is designed to implement the knowledge network in the technology parks, considering the key factors of success (cultural factors, information technology, knowledge processes and human resources). As can be seen, in this model are not mentioned environmental factors and external influences.

Therefore, considering the importance of the subject and purpose of the research, designing a suitable model for knowledge network.

Consequently, the researcher endeavors to fill the above-mentioned gaps due to the importance of the proper design of the knowledge network. In this regard, the intention is to identify the components of the knowledge network and the design of the native model for research organizations For the first time such as the Petroleum Research Institute, to help organizations implement the most successful of these networks and to provide a platform for further research by experts in this field.

\section{Research Methodology}

This research, in terms of purpose, is applied because aims to design a knowledge network model in the Research Institute of Petroleum Industry to improve the quality of knowledge management and contribute to the organizational efficiency of the research institute. Also, in terms of research methodology, a survey method has been carried out using a semi-structured interview with an exploratory approach. To collect qualitative data, statistical population of this research was 9 managers of the key projects of the research institute of petroleum industry who selected based on predetermined indicators. Given that in qualitative research methods, probabilistic sampling methods are not used, and also the aim is not creating a sample or extracting statistical results, so in this research, the sampling method is purposeful. In this research, the nature of the sampling repeat has been observed. If the researcher concludes that the responses or interviews with informed individuals are somewhat similar to each other, which lead to duplication of responses or interviews, and there is no new data in them, the number of interviews is enough, and then the interview was stopped. To design the interview questions, and to identify and analyze the factors involved in designing the knowledge network model at the research institute of the petroleum industry, in the first stage, printed and non-printed resources were investigated and the primary dimensions of the knowledge network identified and extracted. After conducting the interviews and then to analyze the extracted data, the researcher used thematic analysis method using the following approach: 


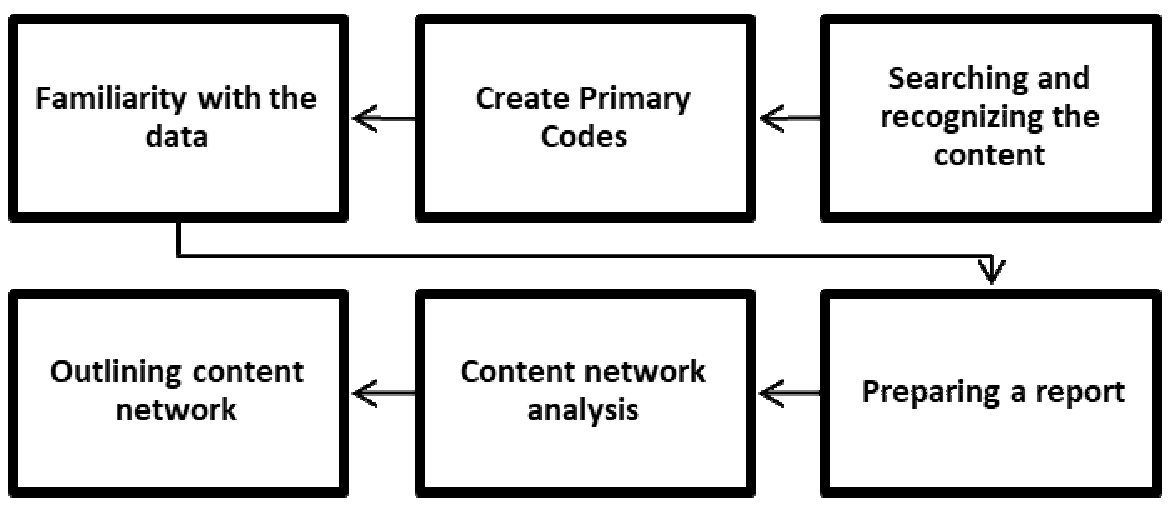

Fig1. The process of data analysis using the method of analysis (Abedi Jafari et al., 2011)

After presenting the basic knowledge network in the qualitative section, the results of qualitative data (through interviewing) evaluated quantitatively. The mechanism used to collect data was a researcher-made questionnaire. Of the 226 researchers with indicators such as (1) Familiar with knowledge management issues, (2) Participate in training courses for the aggregation of projects knowledge, were asked to answer questions. Then, using the exploratory factor analysis of the results obtained, structuring and the initial structure were identified. In the next step, confirmatory factor analysis was used to confirm and present the final model.

Considering the above-mentioned issues, the researcher has taken steps in this study based on the following table:

Table1. Research methodology

\begin{tabular}{|c|c|c|c|c|}
\hline Phase1 & $\begin{array}{c}\text { Investigation of Theoretical } \\
\text { Foundations }\end{array}$ & $\begin{array}{l}\text { Library } \\
\text { Studies }\end{array}$ & - & $\begin{array}{c}\text { Identification of constituent } \\
\text { dimensions of knowledge } \\
\text { network }\end{array}$ \\
\hline Phase2 & Qualitative data collection & Qualitative & $\begin{array}{l}\text { Semi- } \\
\text { structured } \\
\text { interview }\end{array}$ & $\begin{array}{c}\text { Designing interview } \\
\text { questions and collecting } \\
\text { qualitative data based on } \\
\text { the dimensions identified in } \\
\text { phase } 1 \\
\end{array}$ \\
\hline Phase3 & $\begin{array}{l}\text { Extracting the components of the } \\
\text { knowledge network and presenting } \\
\text { the basic framework }\end{array}$ & Qualitative & $\begin{array}{l}\text { Thematic } \\
\text { analysis }\end{array}$ & $\begin{array}{c}\text { Identifying effective } \\
\text { components and removing } \\
\text { ineffective components in } \\
\text { the Research Institute of } \\
\text { Petroleum Industry }\end{array}$ \\
\hline Phase4 & $\begin{array}{c}\text { Quantitative accreditation of the } \\
\text { designed model based on } \\
\text { exploratory factor analysis }\end{array}$ & Quantitative & SPSS & Exploratory factor analysis \\
\hline Phase 5 & $\begin{array}{c}\text { Quantitative accreditation of the } \\
\text { designed model based on } \\
\text { confirmatory factor analysis }\end{array}$ & Quantitative & LISREL & $\begin{array}{c}\text { Investigation of the } \\
\text { extracted components and } \\
\text { determination of the final } \\
\text { model for fitting }\end{array}$ \\
\hline Phase6 & $\begin{array}{l}\text { Presenting suggested solutions for } \\
\text { implementation of the knowledge } \\
\text { network model at the Research } \\
\text { Institute of Petroleum Industry }\end{array}$ & Qualitative & - & $\begin{array}{c}\text { Providing functional } \\
\text { suggestions }\end{array}$ \\
\hline
\end{tabular}

\section{Findings:}

Question1: What are the components of the Knowledge Network in the Research Institute of Petroleum Industry and what is the conceptual framework (model) for the knowledge network in the research institute?

According to the results of the interviews and the background of the research, it was found that out of the 74 initial components obtained, 26 final components could be introduced for the formation of the knowledge network. The method of interviewing and obtaining qualitative data was semi-structured. In the form of basic concepts, the components and dimensions were then explored. In the preliminary pre-analysis, it was found that the basic concepts that considered for the knowledge network of Research Institute of Petroleum Industry were adopted by the respondents according to the interviewees and the angles of each of the components which were specified, identified, and modeled. The conceptual framework derived from the components obtained is shown in 
Fig 2.

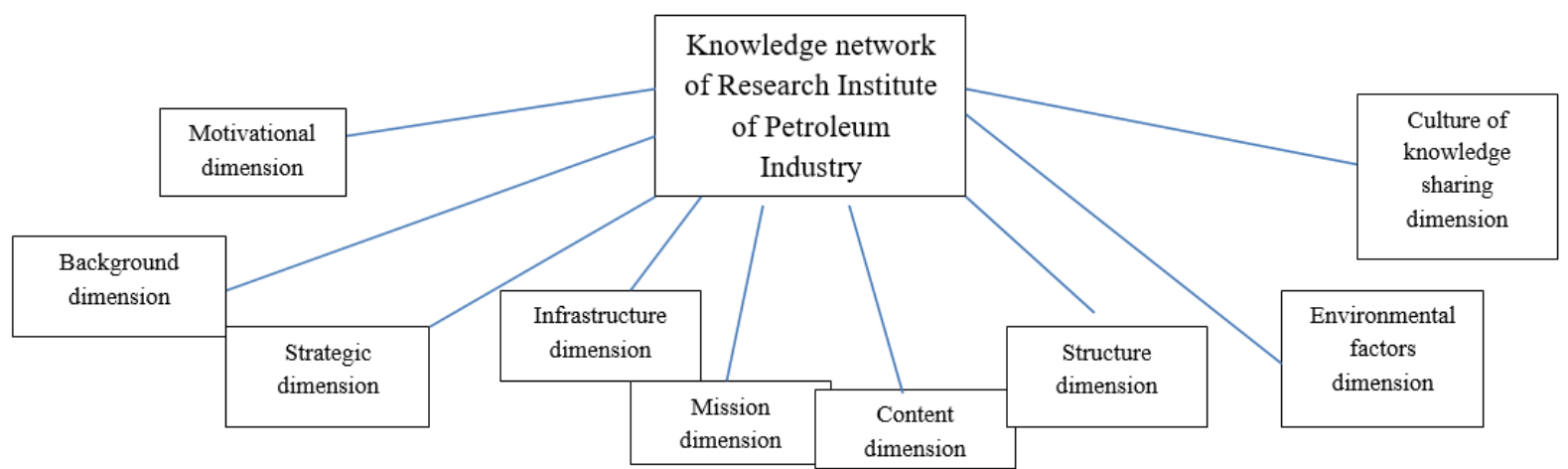

Fig2. Conceptual framework of the components of the knowledge network of the Petroleum Industry Research Institute

According to Figure 1, it was found that the components of the knowledge network are classified into nine sections. All of these components are the final output of ATLAS.ti software, each of which forms part of the research network model of the Research Institute of Petroleum Industry.

Question 2: Is the proposed conceptual framework (model) of knowledge network of Research Institute of Petroleum Industry valid?

Since the initial framework was obtained based on theoretical foundations and qualitative research, the results of the initial analysis revealed that this knowledge network framework was composed of nine main dimensions. The items of each dimension were also introduced based on the analysis of the theme and the existing conditions of the research institute for each dimension. In this step, to identify the factor load of each component of the knowledge network and its appropriateness and validation, individual components of the model were first separately validated and ultimately, the final model was presented. To enter the discussion of factor analysis, first, the researcher needs to determine whether his chosen sample is adequate or not. To this end, the researcher used Bartlett's test in this regard. The KMO index and Bartlett's test result are presented in the following table to examine the adequacy of data for performing factor analysis:

Table2. KMO index and Bartlett's test

\begin{tabular}{|c|c|c|}
\hline .806 & Kaiser-Meyer-Olkin Measure of Sampling Adequacy \\
\hline 2163.761 & Approx. Chi-Square & \multirow{2}{*}{ Bartlett's Test of Sphericity } \\
\hline 2211 & Df & \\
\hline .000 & Sig. & \\
\hline
\end{tabular}

As can be seen, KMO is equal to 0.806 and greater than 0.6 and Bartlett's significant number is less than 0.05 ; therefore, it can be ensured that the sample number has the necessary qualities for factor analysis.

After satisfying the number of samples, the researcher determined the factor loads for each of the dimensions and components. For this purpose, a correlation matrix was prepared from all the variables used in the analysis and share estimation, and then the factors were extracted, and the results were interpreted. The results showed that each of the nine dimensions obtained for the knowledge network has items with a factor load of more than 0.5 and considering these coefficients, the above-mentioned components can be used as components of the dimensions of the knowledge network; So, the nine factors obtained were identified as dimensions of and items credit earned as components of knowledge network. Table 3 demonstrates the dimensions of the knowledge network and the components related to each dimension according to the load factors coefficients.

Table3. The factors extracted from the exploratory factor analysis

\begin{tabular}{|c|c|c|c|c|c|}
\hline $\begin{array}{c}\text { Factor } \\
\text { Name }\end{array}$ & Components & $\begin{array}{c}\text { Load } \\
\text { Factors }\end{array}$ & $\begin{array}{c}\text { Knowledge } \\
\text { sharing culture }\end{array}$ & $\begin{array}{c}\text { Respect for the views } \\
\text { of members and their } \\
\text { expertise }\end{array}$ & 0.823 \\
\cline { 1 - 3 } Strategic & $\begin{array}{c}\text { Cooperation between campuses in } \\
\text { successful implementation }\end{array}$ & 0.846 & & $\begin{array}{c}\text { People's confidence } \\
\text { in the effectiveness of } \\
\text { the knowledge } \\
\text { network }\end{array}$ & 0.778 \\
\cline { 2 - 3 } & $\begin{array}{c}\text { Use open innovation in the } \\
\text { organization }\end{array}$ & 0.858 & & $\begin{array}{c}\text { The positive beliefs } \\
\text { of members in } \\
\text { knowledge and } \\
\text { sharing }\end{array}$ & 0.872 \\
\hline
\end{tabular}




\begin{tabular}{|c|c|c|c|c|c|}
\hline & $\begin{array}{l}\text { Use the scientific capacity of } \\
\text { specialists in the implementation of } \\
\text { organizational strategies }\end{array}$ & 0.853 & & $\begin{array}{l}\text { There is a spirit of } \\
\text { cooperation between } \\
\text { individuals }\end{array}$ & 0.822 \\
\hline & Outsourcing of organization work & 0.824 & & \multirow{2}{*}{$\begin{array}{l}\text { Lack of fear and } \\
\text { resistance in } \\
\text { providing knowledge }\end{array}$} & \multirow[t]{2}{*}{0.893} \\
\hline & \multirow[t]{2}{*}{ Create new ideas in the organization } & \multirow[t]{2}{*}{0.828} & & & \\
\hline & & & & Trust between people & 0.612 \\
\hline & $\begin{array}{c}\text { Commercialization, development and } \\
\text { localization of technologies by the } \\
\text { organization }\end{array}$ & 0.832 & \multirow[t]{8}{*}{ Motivational } & $\begin{array}{l}\text { Welcome to the ideas } \\
\text { of the individual, } \\
\text { especially the best } \\
\text { ideas }\end{array}$ & 0.879 \\
\hline \multirow[t]{8}{*}{$\begin{array}{r}\text { Structura } \\
1\end{array}$} & $\begin{array}{c}\text { The existence of a dynamic and } \\
\text { flexible structure in the knowledge } \\
\text { network }\end{array}$ & 0.868 & & $\begin{array}{l}\text { Financial incentives } \\
\text { for the activity of } \\
\text { individuals }\end{array}$ & 0.924 \\
\hline & $\begin{array}{c}\text { The existence of horizontal } \\
\text { communications in the knowledge } \\
\text { network }\end{array}$ & 0.869 & & $\begin{array}{l}\text { Spiritual incentives } \\
\text { for the activity of } \\
\text { individuals }\end{array}$ & 0.812 \\
\hline & $\begin{array}{l}\text { The existence of a charter for the } \\
\text { knowledge network }\end{array}$ & 0.788 & & $\begin{array}{l}\text { Observing copy } \\
\text { rights of individuals }\end{array}$ & 0.867 \\
\hline & $\begin{array}{c}\text { The existence of regulations of copy } \\
\text { right }\end{array}$ & 0.789 & & $\begin{array}{l}\text { Lack of attention to } \\
\text { the organizational } \\
\text { status of individuals }\end{array}$ & 0.879 \\
\hline & $\begin{array}{l}\text { The role of manager in the } \\
\text { knowledge network }\end{array}$ & 0.766 & & Person's job security & 0.924 \\
\hline & $\begin{array}{l}\text { The role of the coordinator of the } \\
\text { knowledge network }\end{array}$ & 0.855 & & $\begin{array}{c}\text { Creating self- } \\
\text { confidence in people }\end{array}$ & 0.812 \\
\hline & \multirow{2}{*}{$\begin{array}{l}\text { The existence of an informal } \\
\text { structure in the knowledge network }\end{array}$} & 0.805 & & & \\
\hline & & 0.805 & \multirow[t]{7}{*}{ Infrastructure } & $\begin{array}{l}\text { The existence of } \\
\text { information } \\
\text { integrated } \\
\text { management in the } \\
\text { organization } \\
\end{array}$ & 0.709 \\
\hline \multirow[t]{6}{*}{ Content } & $\begin{array}{l}\text { Issues identified and related to } \\
\text { problems of the oil industry }\end{array}$ & 0.901 & & $\begin{array}{c}\text { The existence of } \\
\text { software and } \\
\text { hardware } \\
\text { infrastructure }\end{array}$ & 0.694 \\
\hline & The needs of the oil industry & 0.893 & & $\begin{array}{l}\text { Strong support and } \\
\text { monitoring system }\end{array}$ & 0.728 \\
\hline & $\begin{array}{l}\text { Issues extracted from technology } \\
\text { observation }\end{array}$ & 0.832 & & $\begin{array}{l}\text { Access without time } \\
\text { and place restrictions } \\
\text { to information }\end{array}$ & 0.771 \\
\hline & Topics Required by Researchers & 0.436 & & $\begin{array}{l}\text { Possibility to use } \\
\text { appropriate } \\
\text { communication tools }\end{array}$ & 0.800 \\
\hline & $\begin{array}{l}\text { Issues raised in Research Institute } \\
\text { projects }\end{array}$ & 0.894 & & $\begin{array}{l}\text { The existence and } \\
\text { possibility of } \\
\text { reforming the } \\
\text { organization's } \\
\text { processes }\end{array}$ & 0.795 \\
\hline & Raised ideas & 0.833 & & $\begin{array}{l}\text { Strengthening skills } \\
\text { such as creative } \\
\text { thinking, problem } \\
\text { solving, system } \\
\text { thinking, } \\
\text { communication skills, } \\
\text { conflict management, } \\
\text {.and teamwork }\end{array}$ & 0.838 \\
\hline
\end{tabular}




\begin{tabular}{|c|c|c|c|c|c|}
\hline & $\begin{array}{l}\text { Knowledge areas of different parts of } \\
\text { the organization }\end{array}$ & 0.828 & & $\begin{array}{c}\text { The existence of } \\
\text { think tanks (physical } \\
\text { spaces) }\end{array}$ & 0.750 \\
\hline \multirow{7}{*}{$\begin{array}{l}\text { Intra- } \\
\text { organiza } \\
\text { tional } \\
\text { context }\end{array}$} & $\begin{array}{l}\text { The nature of the network } \\
\text { independence in decision-making and } \\
\text { idea-mongering }\end{array}$ & 0.885 & & $\begin{array}{c}\text { The existence of } \\
\text { database of } \\
\text { specialists }\end{array}$ & 0.675 \\
\hline & $\begin{array}{l}\text { Commitment and support of senior } \\
\text { management of the organization }\end{array}$ & 0.752 & \multirow[t]{9}{*}{ Mission } & Preventing re-works & 0.849 \\
\hline & $\begin{array}{c}\text { Changing organizational approaches } \\
\text { by changing managers }\end{array}$ & 0.638 & & $\begin{array}{l}\text { Prevention of doing } \\
\text { duplicate proposals }\end{array}$ & 0.804 \\
\hline & $\begin{array}{c}\text { The existence of intra-organizational } \\
\text { bureaucracy }\end{array}$ & 0.619 & & Extract new ideas & 0.880 \\
\hline & Organizational organic structure & 0.766 & & $\begin{array}{l}\text { Saving time for } \\
\text { managers due to } \\
\text { aggregation of } \\
\text { opinions }\end{array}$ & 0.826 \\
\hline & $\begin{array}{l}\text { Allocate funds related to network } \\
\text { activity }\end{array}$ & 0.811 & & Deepening the topics & 0.806 \\
\hline & $\begin{array}{l}\text { Existence of long-term strategies in } \\
\text { the organization }\end{array}$ & 0.837 & & $\begin{array}{l}\text { Use all the scientific } \\
\text { ability of researchers }\end{array}$ & 0.821 \\
\hline \multirow[t]{7}{*}{$\begin{array}{r}\text { Environ } \\
\text { mental }\end{array}$} & $\begin{array}{l}\text { Existence of organizational high level } \\
\text { document }\end{array}$ & 0.854 & & $\begin{array}{l}\text { Helping to identify } \\
\text { unskilled } \\
\text { specializations in the } \\
\text { organization and } \\
\text { identify the required } \\
\text { expertise }\end{array}$ & 0.863 \\
\hline & Modeling successful networks & 0.934 & & & \\
\hline & $\begin{array}{l}\text { Existence of positive external } \\
\text { mentality in relation to the } \\
\text { organization }\end{array}$ & 0.931 & & & \\
\hline & $\begin{array}{l}\text { Government public policies in oil } \\
\text { industry }\end{array}$ & 0.875 & & & \\
\hline & The rate of communication between & 0.920 & & & \\
\hline & $\begin{array}{l}\text { scholars outside the organization and } \\
\text { the organization }\end{array}$ & & & & \\
\hline & $\begin{array}{c}\text { Connecting to academic and research } \\
\text { poles in creating and dynamically } \\
\text { networking }\end{array}$ & 0.905 & & & \\
\hline
\end{tabular}

To verify the results of the exploratory factor analysis, the researcher used a confirmatory factor analysis. The first-order factor analysis shows the validity of the relationship between the obvious measures (components) and the size (dimensions). Factor load and $\mathrm{T}$ value test indicate the degree of interference and elimination of items in the design of the knowledge network at the Research Institute. The steps to do confirmatory factor analysis in this study have been designed to scheme the knowledge network as follows: 

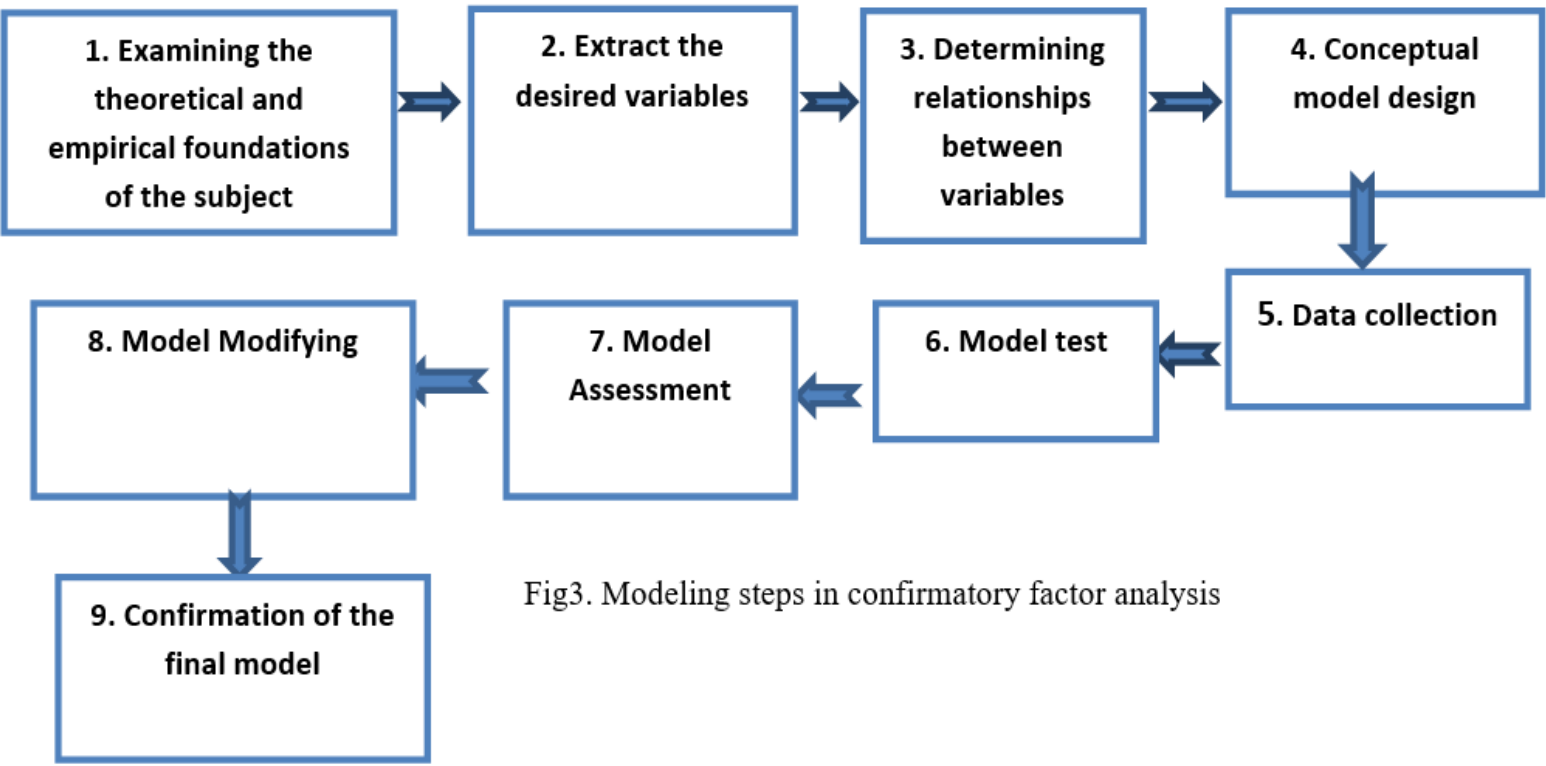

Fig3. Modeling steps in confirmatory factor analysis

The results of confirmatory factor analysis for each of 9 dimensions and components of the knowledge network have a suitable and significant load factor, and are acceptable and favorable for the type of relationship.

In order to discover the relationship between dimensions with the final model of the knowledge network, the researcher used a second-order factor analysis. This factor analysis is used to examine the validity of the relationship between the factors and the final structure, namely, the knowledge network.

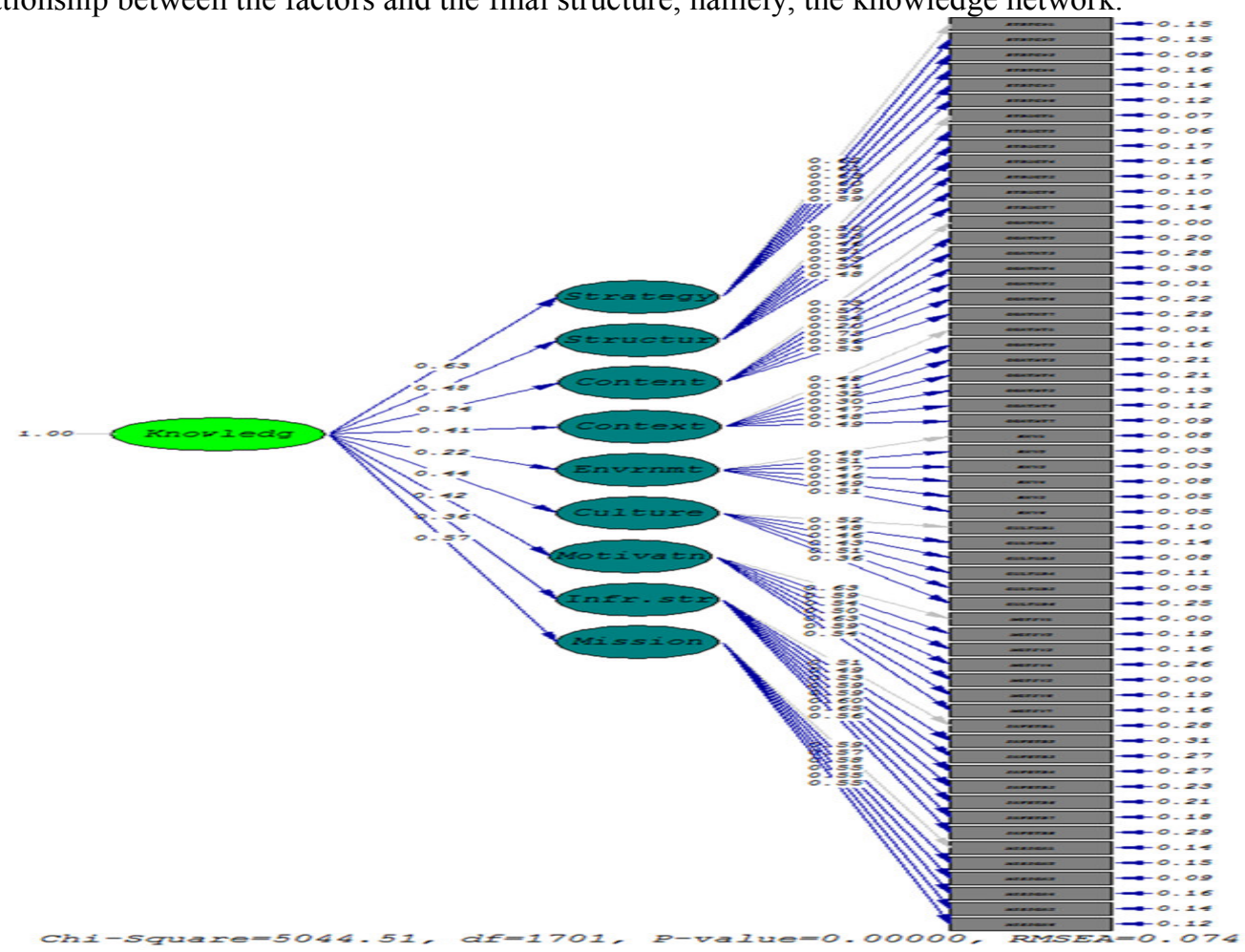

Fig. 4 Standard estimation model in factor analysis of the second-order factor of knowledge network structures

The results obtained from Fig. 4 show that testing knowledge network in the process of modeling, which before the latent factors, namely, the dimensions of the knowledge network, has factor loads greater than 0.3 ; Therefore, the above components are capable of creating the dimensions of the knowledge network. The factor load factors of the above components are as follows:

The strategic dimension of the factor load is 0.63 , and the mission with factor load of 0.57 has the highest factor coefficient, respectively. Environmental and content dimensions have a very weak relationship with factor loadings of 0.22 and 0.20 , respectively. Other factors for structure 0.45 , background 0.41 , knowledge sharing culture 0.44 , motivational 0.42 , and the infrastructure 36.3, was obtained. Factor loadings derived from the type of load are a standard factor and show the relationship between the above dimensions in creating a knowledge 
network.

Also, the results of fitting the model showed that the ratio of $\mathrm{Xi}$ to the degree of freedom was 2.96, which was less than the fixed coefficient criterion of 3 . The RMSEA value was 0.074 as well. It can be concluded that the model has the desired fit. According to the results of Fig. 4, it was found that there is a significant relationship between the observed components and the latent dimension of the knowledge network. Also, since the coefficients of the path $\mathrm{T}$ have been greater than 1.96 , it can be concluded that the fitness of the model is verified.

Therefore, the results obtained from the above analysis (standard factors and $\mathrm{T}$ value test) determined that among the nine factors assigned to the knowledge network, all of them form the final structure of the "Knowledge Network"; In other words, 9 dimensions include: the strategic dimension, structural dimension, content dimension, background dimension (Intra-organization), environmental dimension, the dimension of knowledge sharing culture, infrastructure dimension, motivational dimension and mission dimension with factor load between 0.22 and 0.63 , is formed the knowledge network of the Institute of Petroleum Industry. Therefore, the results indicate that the strategic dimension with factor load of 0.63 has the most important role in establishing the knowledge network. Also, the mission dimension with a factor of 0.57 is in the second priority. The results presented in Table 3 are prioritized as dimensions of the knowledge network.

Table4. Dimensions of the knowledge network and the factor load of each of them

\begin{tabular}{|r|r|r|}
\hline Dimensions of the knowledge network & Factor load & Dimensions effectiveness priority \\
\hline Strategic & 0.63 & 1 \\
\hline Mission & 0.57 & 2 \\
\hline Structural & 0.48 & 3 \\
\hline Knowledge sharing culture & 0.44 & 4 \\
\hline Motivational & 0.42 & 5 \\
\hline Context (Intra-organization) & 0.41 & 6 \\
\hline Infrastructure & 0.36 & 7 \\
\hline Content & 0.24 & 8 \\
\hline Environmental & 0.22 & 9 \\
\hline
\end{tabular}

\section{Discussion and Conclusion}

The third millennium is the knowledge-based era and organizations gain more success that move toward the gaining of the characteristics of learning organizations. In these organizations, knowledge is a key resource, and the proper flow of it among staff is an important tool for achieving innovation in processes, products, and services, effective decision making and adaptation of organizations to a dynamic environment. Knowledge-based organizations are now moving to the transfer of knowledge to networking because managers of these organizations believe that they should be able to innovate and take a different approach.

The purpose of this study was to design a knowledge network of the Petroleum Industry Research Institute. To identify the "aspects and components of the knowledge network at the Petroleum Research Institute", the theoretical literature of knowledge networks was first studied in the Primary resources. The records of the pioneer companies in the world have also been reviewed. After reviewing the printed and non-printed sources, new knowledge was acquired about the knowledge network, which was the basis for designing the interview questions. For the validity of the interview questions, seven experts in the field of KM (knowledge management) were asked to comment on their questions. After confirming the validity of the questions, at the next stage, according to the determined indicators, the interviewees were selected by targeted method and semi-structured interviews were held for each of them. According to the results obtained in the qualitative section, the knowledge network of the petroleum industry research institute has been compiled from nine aspects as follows.

Knowledge sharing culture is one of the most influential dimensions in the network. The results of the research on the cultural dimension are similar to the research findings of Seufert et al. (2006), which refer to cultural dimensions as facilitators of knowledge sharing. Such a similarity is also consistent with the findings of the Davrai's research (2015), which introduced the establishment of appropriate environmental conditions as an influential factor in the network, and the Haghbin's research (2015), which referred to the creation of space for sharing knowledge, and the importance of financial and spiritual incentives. Also, the positive effect of the factors of desire, intention, and behavior for knowledge sharing is in line with the findings of the researches of Wang \& Noe (2010) and Akhavan and Hosseini Sarkhosh (2015).

To create a proper network structure, we should first consider that the more flexible the structures of the network, the more people have the freedom to express their views. This requires that the organizational hierarchy in the network is not dominant and is also less formal. This does not mean ignoring the rules. Of course, there is a need for freedom in the shadow of the rules, but not the official and strict administrative rules in the network. The knowledge network should also be oriented toward decentralization. The results of this study are consistent 
with the following researches of Tavallaei's research (2013), which addressed the structure of the knowledge network; Bieg (2013), which focused on the importance of determining the role and characterization of communications in the knowledge network; Fritsch \& Monz (2010), which found the weak relationships in the network that impede the transfer of knowledge, and Barrett (2004) and Nooteboom (2004) that pointed out the importance of determining roles in the network.

The content of the knowledge network can direct network activities because it is the knowledge of the basis of all decisions and network activities and will play a significant role. The results of the study, Verkoren (2006), emphasize the subject that the content of the knowledge network should be very specific and specialized topics based on the fields of knowledge. The findings of this study are also consistent with the results of Tavallaei (2013) and Abbasi (2012), which refer to the type of knowledge published on the network.

Obviously, for the success of creating the knowledge network from the outset, we should identify the factors of the intra-organizational context and influential environmental factors. One of the most essential influential intra-organization factors can be the commitment and support of senior management of the organization. Out of environmental factors outside of the organization, one can mention the economic conditions and budgets for projects, on the one hand, and sanctions on the other, along with external mentalities that exist in the field of the research institute of the petroleum industry. In this regard, only Tavallaei (2013) and Monge and Eisenburg (1987) investigate the importance of the impact of terrain aspects, such as socioeconomic factors, on the knowledge network, and the findings of this study are almost consistent with their results. The difference between the researches with the present study is that these researches have not pointed to internal environmental factors. From this perspective, the present study is more comprehensive.

Knowledge network can be fruitful in the organization when it converts from a theoretical concept to practical phenomena. This issue will not be achieved except by providing the appropriate infrastructure. Researchers have examined infrastructure from two aspects of information technology and organizational. The results obtained from the infrastructure dimension are consistent with the researches of Dantas \& Bell (2011), Seufert (2006), Du preez (2016), Davari (2015), Haghbin (2015) Abbasi et al. (2012) and Gupta et al. (2007), which investigated the relationship between technology capability and knowledge sharing at group level. Also, in Chrysler (2000) and Beig (2013), information technology and communications tools in knowledge networks are referred to consistently with the findings of the present study.

One of the essential dimensions in the knowledge network, which has a crucial impact on other dimensions of this network, is the strategic dimension, and if this dimension does not exist, then it would not be possible to establish and run a successful network. In fact, the purpose of examining this dimension to reach this conclusion whether the network of knowledge can be plugged into the research institute of the petroleum industry and moved towards the establishment of the knowledge network or not, because at first the knowledge network should be attractive and welcomed by researchers. On the other hand, these people can talk about the attractiveness of the network once they know that the network can be effective in implementing their strategies. Due to the fact that the research institute of petroleum industry is a knowledge-based organization, its strategies emphasize the use of all scientific capacities of researchers. Considering the importance of reducing outsourcing, the knowledge network will be of great help in this regard. It is also due to the establishment of knowledgebased companies by the Research Institute for Oil Industry, whose goal is to develop and localize technology. The presence of a network of experts can help the research institute help the oil industry. Due to the establishment of knowledge-based companies by the Research Institute of Petroleum Industry, whose goal is the development and localization of technology, the presence of a network of experts can assist it in this process. Such a finding has not been mentioned in any of the previous studies.

Another aspect of the knowledge network is motivation. This aspect includes six components, including the reception of individual ideas, especially the best idea, the existence of material incentives for the activities of individuals, respect for intellectual property rights, lack of attention to the organizational status, the existence of job security and self-confidence. The results from this aspect are consistent with Lin (2008) and Malhotra and Dennis (2004). They consider creating an internal and external motivation to implement any knowledge management activity. Abbasi (1391) and De Man (2008) referred to the effective motivational factors in the knowledge network to show their value in the organization, and the results of this study are consistent with their research.

Other side of the knowledge network is mission aspect. The components of this aspect, according to the results of the interviews, include preventing the definition of repetitive proposals, preventing Reworks, extracting new ideas, saving manager's time due to aggregation of opinions, deepening Topics, using all the scientific Ability of researchers, helping to identify unused and required expertise in the organization. According to the analyzes, one can point out that, the full capacity of the members should be used in the knowledge network, since there is a time increasing that each set can subscribe to the knowledge network. In none of the studies have not been paid to this aspect. This aspect is an innovation.

In order to verify the accuracy of the extracted components from exploratory factor analysis, in order to check 
the validity of the relations between the obvious measures and the First factor analysis, and to check the validity of the relationship between the factors with the final construct, the "knowledge network", the second factor analysis was used in this research. To perform factor analysis, the questionnaires were designed according to the extracted components of the qualitative research section. To assess the validity of the questionnaire, seven knowledge management experts were asked to express their points on the questions. After confirming the validity of the questionnaire, in the next stage, 260 managers of the research institutes projects were selected and they were asked to answer the questions. The output of the quantitative phase is the knowledge network model of the Petroleum Industry Research Institute which includes the dimensions and components of the model with their load factor, which has been validated by statistical tests, has been tested and has a valid factor and fit indices. Figure 5 shows the conceptual model of the knowledge network.

-Respecting the opinions of the members
and their expertise
- Assuring people about the effectiveness of
the knowledge network
- Positive beliefs of members to knowledge
and sharing
- Cooperation between individuals
- Lack of person's fear and resistance in
providing
Knowledge
- Trust between individuals

-Issues related to petroleum industry problems

-The future needs of the oil industry Issues extracted from technology observation

- Issues required by researchers

- Issues raised in research institute projects

- Ideas proposed

Knowledge areas of different departments

-Dynamic and flexible structure
- Horizontal communications
-The existence of a constitution
(charter)
-The existence of copy right
-Manager role in the knowledge
network
-The role of coordinator
-The existence of an informal
structure

\section{Knowledge sharing} culture

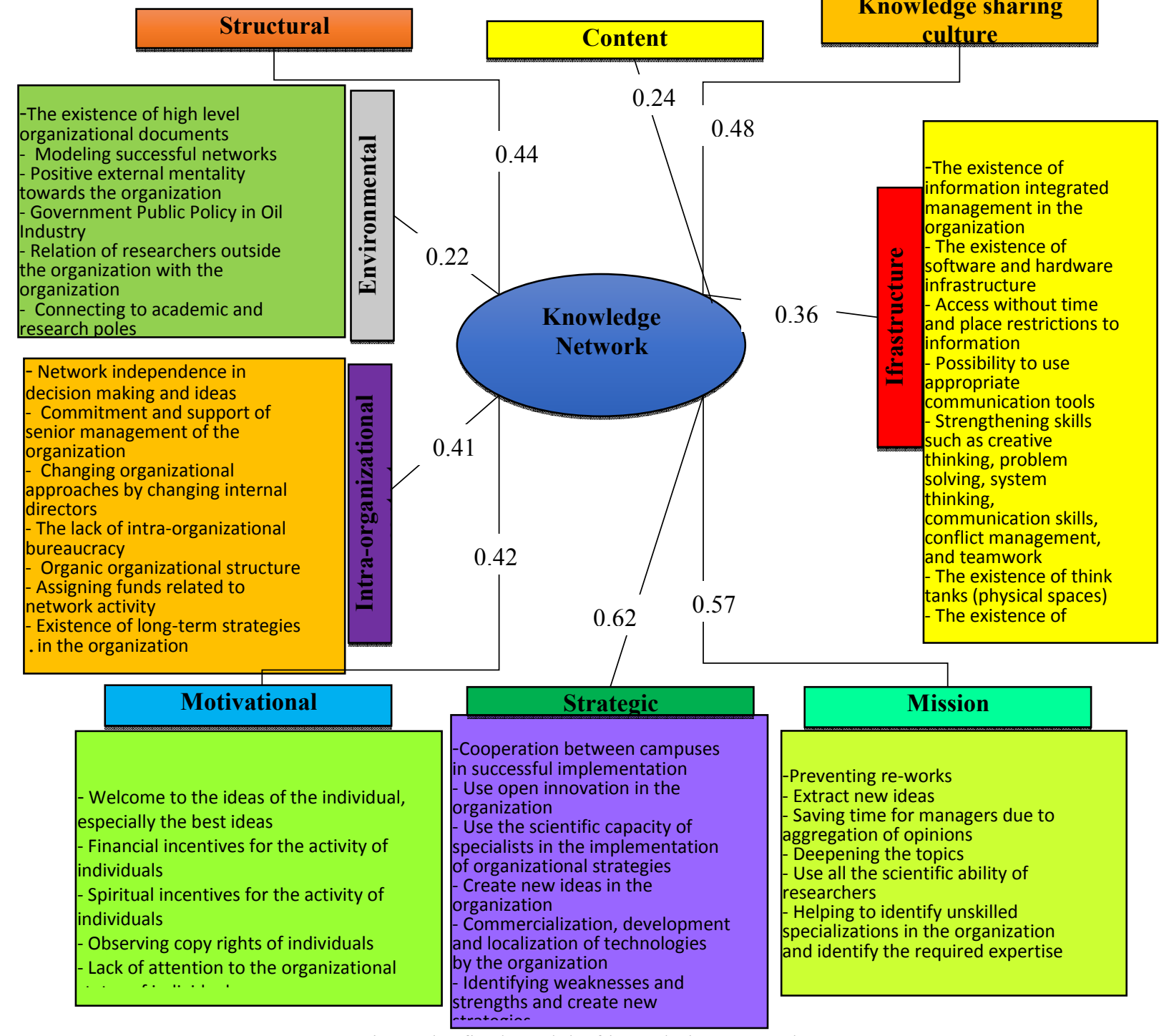

Fig5. The final model of knowledge network 
According to the final model of the knowledge network, the effect of factor load on each of the components, prioritizing each aspect, and the analysis of the research institute of the petroleum industry's status in each aspect, if this research package wants to successfully deploy the knowledge network in command, it is recommended to do the following:

To establish a knowledge network in research centers, and due to the results of this research, the first important factor for the establishment of the knowledge network at the Research Institute of Petroleum Industry is the definition of long-term strategies for the organization. The second factor for creating a knowledge network after defining or changing the strategies of the research institute of the petroleum industry is to identify the mission of the knowledge network at the research institute. The third factor for network deployment is the creation of a proper network structure. The third factor for network deployment is the creation of a proper network structure. In the structure section, the network actors and the role of each of them must be determined. The task orientation greatly hinders the work processes of knowledge and complicates it. Determining relationships within the network is important. Poor communication within the network inhibits or weakens the activities of the creation/sharing of knowledge, while positive relationships created, for example, based on trustbenefit these activities. The fourth factor for implementing the knowledge network is the creation of an appropriate infrastructure for information technology. Without the IT tool, the knowledge network is not able to carry out its mission. The importance of this tool and its role in improving the knowledge sharing process is not overlooked by anyone. Due to the establishment of a network of experience at the Research Institute of Petroleum Industry, the choice of appropriate tools should be considered. The last factor that should be considered for the implementation of the knowledge network is to determine the type of knowledge content. Network knowledge content can be determined through the knowledge strategies of the research institute. Cultural factors, motivational conditions, and environmental factors affect all of the above steps and should always consider these factors.

Since the research institute of petroleum industry is considered as one of the project-based institutions in Iran and one of the Ministry of Oil's research and technology hubs, it is possible to use the aspects and components that have been identified in this project for other similar research centers and five hubs of the petroleum Ministry. Also, in order to spend time and cost, it is possible to use the model for the relationship between the Oil Ministry's research and technology hubs, which is due to the lack of definition of repetitive projects and designs and requires the use of the comprehensive software system that includes all the Ministry of Oil systems and integrates with other systems.

\section{Refrances}

Abbasi, A. and Abbasi, M. (2012), "The role of Knowledge Networks in Transforming Organizations into Knowledge-Based Organizations". 7th Conference on Power Distribution Networks, Amir Kabir University, Tehran.

Abedi Jafari, H., Teslimi, M. S., Faghihi, A. and Sheikhzadeh, M. (2011), 'Thematic Analysis and Thematic Network', A Simple and Effective Way to Explain the Patterns in the Qualitative Data. Strategic Management Thought 5(2), 151-198.

Akhavan, P. and Hosseini Sarkhosh, M. (2015), "Information Management". Journal of Information Processing and Information Management 30(4), 51-84

Asgari, Gh., Eliasi, A. and Ebrahimi Ghadikalei, A. (2014), "Investigating the Role of Knowledge Management Infrastructure in Implementing the Organization Knowledge Network". 1th National Conference on Electrical and Computer Engineering in the North, Mazandaran, Iran.

Barrett, M., Cappleman, S. Shoib, G. and Walsham, G. (2004), "Learning in Knowledge Communities: Managing Technology and Context". European Management Journal 22(1), 1-11.

Beig, L. (2013), “Applying Supply Chain Management Approach to Implementing the Organization Knowledge Network, Case Study: Knowledge Network of Information and Communication Technology". 6th Knowledge Management Conference, Shahid Beheshti University, Tehran, Iran.

Beig, L., Ghavamifar, A., Eghbali, N. and Kharrat, M. (2011), "Providing a New Process for Knowledge Network Risk Management”. 4th Knowledge Management Conference, Tehran, Iran.

Chrysler , D. (2000), "Interview with a Member of the Community of Practice on Corporate Level about Knowledge Management".

Dantas, E. (2006), "The development of knowledge networks in latecomer innovation systems: the Case of PETROBRAS in the Brazilian Offshore Oil Industry". PHD Thesis, University of Sussex, UK.

Davari, Sh. (2015), "Effective Factors in Implementing the Common Knowledge Network among Fellow Organizations". Master's Thesis, Kharazmi University, Tehran.

De Man, A. P. (2008), "Knowledge Management and Innovation in Networks". Cheltenham: Edward ElgarDu.

Du Preez, N. D. (2016), "A Comparative Study about the Formal Design Life Cycle of the Integrated Knowledge Network to Support Innovation". International Conference on Competitive Manufacturing, Stellenbosch, 
South Africa.

Fritsch, M., and Kauffeld-Monz, M. (2010), "The Impact of Network Structure on Knowledge Transfer: an Application of Social Network Analysis in the Context of Regional Innovation Networks." Annals of Regional Science 44(1), 21-38.

Gupta, S. \& et.al (2009), 153-160. "Knowledge Management in Academic Institute and Role of Knowledge Managers." Available at http://library.igcar.gov.in/readit2007/conpro/s5/S5_1.pdf

Haghbin, M., Tavallaei, R., Shokoohyar, S., \& Feizi, A.( 2015), "Identifying Relationships of Key Indicators of the Establishment of Knowledge Networks in Science and Technology Parks of the University of Tehran by DEMATEL Method", Eighth National Knowledge Management Conference, Tehran.

Hassanzadeh, M. (2008), "Knowledge Management in the Organization". Ketab e Mah Kolliat (43), 15-20.

Johnson, J. D. (2009), "Managing Knowledge Networks". United Kingdom: Cambridge University Press.

Kamali Tabrizi, F. (2011), "Developing a Knowledge Management Strategy for the Petroleum Industry Research Institute. Research Project". Research Institute of Petroleum Industry, Tehran.

Karimi, S., and Nasr, A. R.( 2014), "Methods of Analysis of Interview Data". Research 4(1), 71-94.

Malhotra, A., and A. Majchrzak. (2004), "Enabling Knowledge Creation in Far-flung Teams: Best Practices for IT support and Knowledge Sharing". Journal of Knowledge Management 8(4), 75-88.

Monge, P., and E. Eisenberg. (1987), "Emergent Communication Networks. In Handbook of Organisational Communication", by L. Putnam, K. Roberts, \& L. Porter (eds.) F. Jablin, 304-342. Newbury Park, CA: Sage.

Monavvarian, A., \& Asgari, N. (2009), "Organization in the Age of Industry. Information and knowledge". Tehran: Tehran University Publications.

Nooteboom, B. (2004), "Inter-Firm collaboration, Learning and Networks : an Integrated Approach". London: Routledge.

Okunoye, A. (2003), "Implementation and Use of Global Intranet: Case of a Distributed Research Organisation". the 4th Global Information Technology Management World Conference. Calgary Canada.

Pugh, K., and L. Prusak. (2013), "Designing Effective Knowledge Networks." MIT Sloan Management Review 55(1), 79-88.

Seufert, A., Von Krogh, G. and Bach, A.(2006), "Towards Knowledge Networking". Journal of Knowledge Management 3(3), 180-190.

Sheng, M.L. (2013), "Knowledge Barriers, Knowledge Transfer, and Innovation Competitive Advantage in Healthcare Settings". Management Decision 51( 3), 461-478.

Tang, Ying-Sze. (2010), "The roles of Network in the Knowledge Transfer Process". Master's Thesis, Halmstad University.

Tavallaei, R. (2013), "Designing a Pattern of Knowledge Development in Petroleum Industry Research and Technology Hubs". PhD thesis, Allameh Tabataba'i University, Tehran.

Verkoren, Willemijn. (2006), "Learning by NGOs: Retaining and Using Knowledge for Development". available at: https://www.thefreelibrary.com/Knowledge+networking\%3a+implications+for+peacebuilding+activities.a0186384444.

Wang, S., and Noe, R. A. (2010), "Knowledge Sharing: A Review and Directions for Future Research". Human Resource Management Review 20(2), 115-131.

Whitall, D. R. (2007), "Network Analysis of a Shared Governance System". PHD Thesis, Portland State University. 